Published in final edited form as:

Ann Rheum Dis. 2019 November 01; 78(11): 1497-1504. doi:10.1136/annrheumdis-2018-214868.

\title{
Does immunological remission, defined as disappearance of autoantibodies, occur with current treatment strategies? A long- term follow-up study in rheumatoid arthritis patients who achieved sustained DMARD-free status
}

\author{
Debbie M. Boeters ${ }^{1}$, Leonie E. Burgers ${ }^{1}$, René E.M. Toes ${ }^{1}$, Annette H.M. van der Helm-van \\ Mil $^{1,2}$ \\ ${ }^{1}$ Department of Rheumatology, Leiden University Medical Center, Leiden, the Netherlands \\ ${ }^{2}$ Department of Rheumatology, Erasmus University Medical Center, Rotterdam, the Netherlands
}

\begin{abstract}
Objectives-Sustained disease modifying antirheumatic drug (DMARD)-free status, the sustained absence of synovitis after cessation of DMARD-therapy, is infrequent in autoantibodypositive RA, but approximates cure (i.e. disappearance of signs and symptoms). It was recently suggested that immunological remission, defined as disappearance of anticitrullinated protein antibodies (ACPA) and rheumatoid factor (RF), underlies this outcome. Therefore, this long-term observational study determined if autoantibodies disappear in RA-patients who achieved sustained DMARD-free remission.
\end{abstract}

Methods-We studied 95 ACPA- and/or RF-positive RA-patients who achieved DMARD-free remission after median 4.8 years and kept this status for the remaining follow-up (median 4.2 years). Additionally, 21 autoantibody-positive RA-patients with a late flare, defined as recurrence of clinical synovitis after a DMARD-free status of $\geq 1$ year, and 45 autoantibody-positive RApatients who were unable to stop DMARD-therapy (during median 10 years) were studied. AntiCCP2 IgG, IgM and RF IgM levels were measured in 587 samples obtained at diagnosis, before and after achieving DMARD-free remission.

Results- $12.8 \%$ of anti-CCP2 IgG positive RA-patients had seroreverted when achieving remission. In RA-patients with a flare and persistent disease this was $8.3 \%$ and $5.7 \%$, respectively

\footnotetext{
Address of correspondence: Debbie M. Boeters, department of Rheumatology C1-R, Leiden University Medical Center, PO Box 9600 , Leiden 2300 RC, the Netherlands, Tel.: +31 71 5265653, Fax: +31 71 5266752, D.M.Boeters@lumc.nl.

Contributorship

DMB, LEB and AHMvdHvM contributed to the conception and study design. DMB analysed the data. DMB, LEB, REMT and

AHMvdHvM contributed to interpretation of the data. DMB and AHMvdHvM wrote the first version of the manuscript and LEB and REMT revised it critically. DMB, LEB, REMT and AHMvdHvM read and approved the final manuscript.

Competing Interests

None.

Ethical Approval

The study was approved by the local medical ethics committee, which is named 'Commissie Medische Ethiek'. All patients signed informed consent.

Data Sharing Statement

Data can be requested from the corresponding author
} 
$(\mathrm{p}=0.63)$. For anti-CCP2 IgM and RF IgM similar results were observed. Evaluating the estimated slope of serially measured levels revealed that RF-levels decreased more in patients with than without remission $(\mathrm{p}<0.001)$; the course of anti-CCP2 levels was not different $(\mathrm{p}=0.78)$.

Conclusions-Sustained DMARD-free status in autoantibody-positive RA was not paralleled by an increased frequency of reversion to autoantibody-negativity. This form of immunological remission should therefore not be a treatment target.

\section{Keywords}

rheumatoid arthritis; autoantibodies; sustained DMARD-free remission

\section{Introduction}

Sustained DMARD (disease-modifying antirheumatic drug)-free status is defined as sustained absence of synovitis after cessation of all DMARD-therapy and is increasingly achievable by patients with rheumatoid arthritis (RA).[1] This status is also characterised by normalisation of functional status and lower levels of fatigue, pain and morning stiffness and is currently considered the best possible outcome of RA.[1] Absence of anti-citrullinated protein antibodies (ACPA) at disease presentation is an important predictor of achievement of sustained DMARD-free remission, however with current treatment strategies this outcome is also observed in 10\% of ACPA-positive RA.[1-5]

The pathophysiological role of ACPA in RA development or progression is not exactly known. ACPA can be present years before the onset of joint symptoms and disease, indicating that the mere presence of ACPA is not enough to develop disease.[6,7] Studies in the pre-clinical phase have shown that the ACPA immune response matures once disease onset is approached; as characterized by an increase in ACPA-level, isotype-usage, avidity and the number of citrullinated epitopes recognized by ACPA.[8-11] In addition, there are changes in Fc glycosylation before RA onset.[12] Once RA is established the ACPA immune response does not mature any further.[13] Besides ACPA, also RF can be present years before disease onset.[6,7] Since autoantibodies are considered to have a prominent role in seropositive RA and precede symptom development, it is tempting to hypothesize that changes in the autoantibody response occur before or at the time when clinical disease has been extinguished, as is the case when sustained DMARD-free remission is reached. In this light, it was recently suggested that disappearance of autoantibodies is an hallmark of immunological remission and might characterize patients who are able to achieve drug-free remission.[14]

However, so far this hypothesis has not been thoroughly investigated. In a few studies seroconversion and -reversion during follow-up of early arthritis and RA-patients were investigated. The observations described indicate that both are infrequent and not associated with relevant outcomes such as radiographic damage, functional status or the disease activity score.[15-18] In only one study the association between seroreversion and drug-free remission was analysed and no association was observed.[19] However, autoantibody levels were only determined at disease presentation and at 1-year of follow-up, thus generally years 
before achievement of drug-free remission. In addition, follow-up of patients after the achievement of drug-free remission was limited.[19]

We aimed to increase the understanding of the long-term course of RA-related autoantibodies in patients who had achieved the closest available proxy of cure of RA. Therefore, we investigated the association between ACPA and RF seroreversion and achievement of sustained DMARD-free remission in a unique population of RA-patients with available serum samples at the time of remission and with a long follow-up duration after achievement of DMARD-free status.

\section{Methods}

Patients

Patients were retrieved from the Leiden Early Arthritis Clinic (EAC) cohort, which is an inception cohort that includes patients with clinically confirmed arthritis and symptom duration $<2$ years. At baseline, patients and rheumatologists completed questionnaires, joint counts were performed and blood samples were collected. Follow-up visits were scheduled and blood samples were taken at 3-4 months, 6-8 months, 12 months, 18 months, 24 months and yearly thereafter. Between 1993 and 2014 3,473 patients were consecutively included, of which 1,586 patients had a clinical diagnosis of RA and also fulfilled 1987 or 2010 RAclassification criteria during the first year of follow-up.[20,21] Of these, 941 patients were ACPA- and/or RF-positive at baseline.

Treatment strategies changed over time. In general, patients included in 1993-1995 were initially treated with nonsteroidal anti-inflammatory drugs, patients included in 1996-1998 with mild DMARDs (hydroxychloroquine or sulphasalazine) and patients included $\geq 1999$ were initially treated with methotrexate. When this treatment failed, another conventional DMARD was initiated or added. A biological DMARD was allowed in patients who failed on $\geq 2$ conventional DMARDs. Medication used by all studied patients during the observed follow-up period is shown Supplementary. DAS44-guided treatment became common from 2005 onwards with tapering and eventually stopping of treatment if DAS44 remained $<2.4$ and synovitis was absent at clinical joint examination, and intensifying treatment in case of DAS44 $\geq 2.4$.

Of the 1,586 RA-patients medical files were studied on occurrence of sustained DMARDfree remission until April 2017. This outcome was defined as absence of synovitis (by physical examination) during the complete available follow-up after cessation of all DMARD-therapy (including biologics and systemic and intra-articular corticosteroids); this latter follow-up should have been $\geq 1$ year. Patients who experienced a flare of clinical synovitis early or late after DMARD-cessation were considered as not in sustained DMARD-free remission. The date of sustained DMARD-free remission was the date one year after DMARD-cessation. Patients who did not achieve remission were censored at the date when medical files were explored or at an earlier date when they were lost to follow-up or had died. 95 of 941 ACPA- and/or RF-positive RA-patients achieved sustained DMARDfree remission after a median follow-up of 4.8 years (Figure 1). After achievement of 
sustained DMARD-free remission, patients were additionally followed for median 4.2 years. Except for 1 patient, all patients were included from 1999 onwards.

In addition, 21 autoantibody-positive RA-patients who experienced a late flare were studied. This was defined as recurrence of clinical synovitis after having been in DMARD-free remission for $>1$ year after DMARD-cessation; the median duration of being in DMARDfree remission before a flare occurred was 2.2 years. As control, 45 autoantibody positive RA-patients who were unable to stop DMARD-therapy because of persistent swollen joints during follow-up, were evaluated. These patients were selected from the group of autoantibody-positive RA-patients who never achieved DMARD-free remission based on comparable inclusion period and on available serum samples at baseline, 1-year and at 7-8 years follow-up or earlier in case patients had a shorter follow-up duration.

Median total follow-up of the studied patients was 10 years and was comparable between the studied groups.

\section{Serological measurements}

Anti-cyclic citrullinated peptide 2 (Anti-CCP2) IgG and RF IgM were measured in 587 serum samples obtained at diagnosis, before and after achieving DMARD-free remission, using enzyme-linked immunosorbent assays as described previously.[22,23]. An overview of the measured samples during follow-up for the different groups is depicted in Figure 2. Of each patient a median of three samples was measured. In addition, anti-CCP2 IgM was measured in the first and last available serum sample of each patient. Pooled serum samples of highly positive patients were used in all plates to generate standard curves. Autoantibody levels were estimated by interpolation from these standard curves and were expressed in arbitrary units per millilitre. To ascertain that the obtained signal within the anti-CCP2 IgM ELISA was citrulline-specific, samples were considered positive when the signal was higher than the mean+2SD of serum samples of healthy control subjects which were included on each plate. In addition, the difference between the signal against the citrullinated peptide and the unmodified arginine peptide had to be more than 0.1 (OD>0.1).

\section{Statistical analyses}

The difference between the first and last available serum sample was used to calculate the proportion of patients with seroreversion. This was performed separately for patients positive for anti-CCP2 IgG, anti-CCP2 IgM and RF IgM. Differences in seroreversion between the three patient groups were compared with the Fisher exact test. To test whether changes in ACPA- and/or RF-levels during follow-up were associated with achievement of sustained DMARD-free remission, Cox proportional hazards regression analyses were performed with time till achievement of remission as outcome. For these analyses, patients with a late flare were combined with patients with persistent RA as one group. Changes in anti-CCP2 IgG and RF IgM level per year were estimated with linear regression analyses for each patient individually. These changes in levels over time were used as predictor in Cox proportional hazards regression analyses. Antibody levels below the detection limit were imputed with a value of zero. SPSS version 23.0 (IBM) was used and p-values $<0.05$ were considered significant. 


\section{Results}

\section{Patient characteristics}

Baseline characteristics of the studied autoantibody-positive patients are presented in Table 1 and are similar between the different groups, with the exception that patients who achieved sustained DMARD-free remission were less frequently ACPA-positive.

\section{Anti-CCP2 IgG and RF IgM seroreversion were not associated with achievement of sustained DMARD-free remission}

First, anti-CCP2 IgG levels were serially measured in the three different patient groups (Figure 3A). Of anti-CCP2 IgG positive RA-patients who achieved sustained DMARD-free remission, $12.8 \%$ had reverted to anti-CCP2 IgG negativity around the time of remission (Figure 4A). However, for RA-patients with a late flare or with persistent disease, seroreversion was observed in $8.3 \%$ and $5.7 \%$, respectively, which was not significantly different from patients who achieved sustained DMARD-free remission $(\mathrm{p}=0.63)$.

Patients with seroreversion had lower median anti-CCP2 IgG levels at disease presentation than patients without seroreversion ( $42 \mathrm{AU} / \mathrm{ml}$ and $420 \mathrm{AU} / \mathrm{ml}$ respectively, $\mathrm{p}<0.001)$. Ever use of biological DMARDs was comparable in patients with and without seroreversion (33.3\% and $31.8 \%$ respectively, $\mathrm{p}=1.00$ ).

Similar results were observed for RF IgM (Figure 3B, Figure 4B). RF-positive patients who achieved sustained DMARD-free remission had seroreversion in $19.7 \%$, whereas this occurred in $6.3 \%$ and $14.6 \%$ of patients with a late flare and with persistent disease, respectively ( $\mathrm{p}=0.44$, Figure 4B). RF IgM levels were lower in patients with seroreversion than in patients who remained positive for $\mathrm{RF} \operatorname{IgM}(19 \mathrm{IU} / \mathrm{ml}$ and $53 \mathrm{IU} / \mathrm{ml}$ respectively, $\mathrm{p}=0.003$ ). Thus, ACPA or RF seropositive RA-patients who achieved sustained DMARDfree remission did not become more frequently seronegative than patients who did not achieve remission.

\section{Changes in RF IgM levels were larger in patients with sustained DMARD-free remission than in patients with persistent RA}

Next, it was evaluated whether changes in autoantibody levels during the total follow-up period differed between patients. The change in anti-CCP2 IgG level per year was not associated with achievement of sustained DMARD-free remission $(\mathrm{p}=0.66)$. For RF IgM positive patients, the change in RF-level was associated with achievement of sustained DMARD-free remission; for every 10-unit decrease in RF IgM level per year the rate of sustained DMARD-free remission increased by 16\% ( $\mathrm{p}<0.001$ ). Thus, seropositive RApatients who achieved sustained DMARD-free remission did not have disappearance of autoantibodies, however there was a significant decrease of RF IgM levels in patients who achieved sustained DMARD-free remission compared to patients who did not.

\section{Anti-CCP2 IgM seroreversion was not associated with sustained DMARD-free remission}

Finally, the proportion of patients seroreverting from anti-CCP2 IgM positive to negative was studied as we hypothesized that if the ACPA immune response had changed in patients 
who achieved remission, this could be reflected by a decreased presence of anti-CCP2 IgM, since IgM is an indication of an ongoing immune response. Of anti-CCP2 IgG positive patients, 25-29\% were also positive for anti-CCP2 $\operatorname{IgM}$ at disease presentation within the different groups (Figure 5A). During follow-up 31\% (4/13) of the anti-CCP2 IgG and IgM positive patients who achieved DMARD-free remission seroreverted from positive to negative anti-CCP2 IgM (Figure 5B). For patients with a late flare and patients with persistent RA this occurred in 100\% (3/3) and 60\% (6/10) respectively. Thus, patients who achieved sustained DMARD-free remission and who were seropositive for anti-CCP2 IgM at disease presentation did not serorevert more frequently than patients who did not achieve remission.

\section{Sensitivity analyses}

To investigate whether our results were driven by patients with autoantibody levels fluctuating around the cut-off, analyses were performed in patients with baseline autoantibody levels above the median which showed that none of the anti-CCP2 IgG positive patients had seroreverted. For RF IgM, $8 \%$ of patients who achieved sustained DMARD-free remission, none of the patients with a late flare, and $10 \%$ of patients with persistent disease had seroreverted.

Finally, analyses were repeated in patients who had a follow-up duration of $\geq 4.2$ years after achievement of sustained DMARD-free remission (i.e. within $50 \%$ of patients with the longest follow-up after DMARD-cessation). This analysis was performed to verify if patients with shorter follow-up after DMARD-cessation influenced the results, as these patients could be at risk of developing a late flare. Of anti-CCP2 IgG positive RA-patients who achieved sustained DMARD-free remission, 6.3\% had reverted to anti-CCP2 negativity around the time of remission, which was not different from patients with a late flare and with persistent disease, who had seroreversion in $8.3 \%$ and $5.7 \%$, respectively $(\mathrm{p}=1.00)$. Of RF IgM positive RA-patients who achieved sustained DMARD-free remission, 16\% had reverted to RF IgM negativity. Of patients with a late flare and with persistent disease this occurred in $6.3 \%$ and $15 \%$, respectively $(\mathrm{p}=0.78)$.

\section{Discussion}

Currently a sustained DMARD-free status is the best possible clinical outcome as, per definition, clinically apparent synovitis is persistently absent and patients in this status also have resolution of symptoms and normalized functional status.[1] This outcome is achievable in autoantibody-positive RA, although with a lower frequency than in autoantibody-negative RA. The biological nature underlying this type of persistent remission is unknown. It was recently suggested that it is characterized by disappearance of autoantibodies.[14] The present large observational study with a unique, long follow-up period and with samples measured at the time of remission, explored this hypothesis. No association between remission and reversion to autoantibody negativity was demonstrated. Hence, our data do not support the presumption that immunological remission is characterized by disappearance of autoantibodies. 
To our knowledge this is the first study in which seroreversion rates in patients with longstanding DMARD-free status were investigated. Importantly, for both ACPA and RF seroreversion was infrequent (16.4\% for RF IgM and 9.6\% for CCP2 $\operatorname{IgG}$ ) and not related to clinical outcome. In previous studies in patients with established RA who were treated with DMARDs and thus had persistent disease, similar seroreversion rates were observed.[18,2426] Thus, seroreversion rates observed here are in line with previous findings in RA and are not increased in patients with sustained DMARD-free status.

When analyses were repeated in patients with high autoantibody levels (above the median) at baseline, seroreversion for anti-CCP2 IgG was not observed anymore, and seroreversion for RF IgM was less frequent than in the whole group of autoantibody-positive patients. This suggests that the observed seroreversion rates were mainly the result of patients who fluctuated around the cut-off level, and therefore that true seroreversion of ACPA and RF is only sporadically observed.

Although no association between remission and seroreversion was observed, patients who achieved a DMARD-free status had a larger decrease in RF-levels during follow-up than patients who did not achieve this outcome. Several studies have shown that improvement in disease activity is accompanied by decrease in RF-levels[26-30], although some other studies did not observe this.[18,19,31] A unique feature of this study is that a prolonged period of absence of clinical synovitis is observed, which is a much more stringent outcome than improvement in disease activity scores. Previous studies showed no relation between ACPA-levels and disease activity and our data also demonstrated no relation with sustained DMARD-free status.[26-30]

Previously it was shown that anti-CCP2 IgM remains present in RA-patients during treatment in a persistent disease phase, suggesting that the anti-CCP immune response is continuously reactivated.[32] Interestingly, we have shown here that anti-CCP2 IgM also remained persistently present in patients who achieved sustained DMARD-free remission. This suggests that even in patients who are clinically cured, the anti-CCP response is persistently activated. ACPA characteristics other than level and IgM and IgG isotypes were not investigated. However, it is known that ACPA-level is highly associated with ACPA fine specificity and the number of ACPA isotypes.[33] Based on this, it can be presumed that these characteristics were also not different between patients that did or did not achieve a sustained DMARD-free status. Nonetheless, we do not rule out that these, or other characteristics of the autoantibody response in RA correlate with the induction of sustained DMARD-free remission. Altogether, disappearance of clinical disease is not accompanied by changes in the humoral ACPA response in serum. Thus, whereas for RA development it is not yet elucidated whether ACPA play a role in the pathophysiology or act as bystander, the present data suggest that the ACPA-response does not explain the maintained resolution of clinical disease. Whether other immunologic markers, for instance changes in characteristics of autoantibody expressing B-cells, associate with this phenotypic outcome, and therefore would be a better definition of immunological remission, is subject of further research. 
A strength of this study is that patients had a long follow-up period also after DMARDcessation (median 4.2 years after achievement of sustained DMARD-free remission, thus median 5.2 years after DMARD-stop). This follow-up time supports the validity of the outcome, as patients with an early flare after DMARD-stop were never considered to be in remission, and also patients with a late flare were identified and excluded from the group of patients that achieved sustained DMARD-free remission. Late flares generally occurred 2.2 years after DMARD-cessation and the large majority of patients were followed for a longer period of time after DMARD-stop. A sub-analysis in the patients who were followed for $>4$ years after achieving remission showed similar results, showing the robustness of the data in this respect. Of course, we do not know if the autoantibody-positive patients will get a flare of disease after an even longer follow-up period; this is subject of future studies. Some of the patients have been discharged from the outpatient clinic because of prolonged absence of synovitis and symptoms. Importantly, it is plausible that if symptoms will recur patients will return to our clinic since the Leiden University Medical Center is the only referral center in a health care region of $\sim 400,000$ inhabitants and has very easy access services, allowing that patients with symptoms suspicious of RA are seen within 1 week.[34]

Previously, it was suggested that remission can be defined according to different conditions and presence of immunological remission, defined as the disappearance of autoantibodies, was suggested to be the deepest form of remission. In this long-term study, we were able to analyse a large number of ACPA-positive patients who achieved sustained DMARD-free remission. In this unique dataset we observed that disappearance of autoantibodies rarely occurred, and that patients who achieved the best possible outcome of RA did not become more often seronegative than patients with persistent disease. Therefore, in our view, this definition of immunological remission, should not be a long-term treatment target.

\section{Supplementary Material}

Refer to Web version on PubMed Central for supplementary material.

\section{Acknowledgements}

The authors thank Gerrie Stoeken and Annemarie Dorjée for performing the experiments.

Funding

This project has received funding from the European Research Council (ERC) under the European Union's Horizon 2020 research and innovation programme (Starting grant, agreement No 714312), the Dutch Arthritis Foundation and the Innovative Medicines Initiative 2 Joint Undertaking under grant agreement No 777357. This Joint Undertaking receives support from the European Union's Horizon 2020 research and innovation programme and EFPIA.

\section{References}

1. Ajeganova S, van Steenbergen HW, van Nies JaB, et al. Disease-modifying antirheumatic drug-free sustained remission in rheumatoid arthritis: an increasingly achievable outcome with subsidence of disease symptoms. Ann Rheum Dis. 2016; 75:867-73. DOI: 10.1136/annrheumdis-2014-207080 [PubMed: 25972519]

2. van der Woude D, Young A, Jayakumar K, et al. Prevalence of and predictive factors for sustained disease-modifying antirheumatic drug-free remission in rheumatoid arthritis: results from two large 
early arthritis cohorts. Arthritis Rheum. 2009; 60:2262-71. DOI: 10.1002/art.24661 [PubMed: 19644846]

3. Rooy de DPC, van der Linden MPM, Knevel R, et al. Predicting arthritis outcomes-what can be learned from the Leiden Early Arthritis Clinic? Rheumatology. 2011; 50:93-100. DOI: 10.1093/ rheumatology/keq230 [PubMed: 20639266]

4. van der Kooij SM, Goekoop-Ruiterman YPM, de Vries-Bouwstra JK, et al. Drug-free remission, functioning and radiographic damage after 4 years of response-driven treatment in patients with recent-onset rheumatoid arthritis. Ann Rheum Dis. 2009; 68:914-21. DOI: 10.1136/ ard.2008.092254 [PubMed: 18662933]

5. Haschka J, Englbrecht M, Hueber AJ, et al. Relapse rates in patients with rheumatoid arthritis in stable remission tapering or stopping antirheumatic therapy: interim results from the prospective randomised controlled RETRO study. Ann Rheum Dis. 2016; 75:45-51. DOI: 10.1136/ annrheumdis-2014-206439 [PubMed: 25660991]

6. Rantapää-Dahlqvist S, de Jong BAW, Berglin E, et al. Antibodies against cyclic citrullinated peptide and IgA rheumatoid factor predict the development of rheumatoid arthritis. Arthritis Rheum. 2003; 48:2741-9. DOI: 10.1002/art.11223 [PubMed: 14558078]

7. Nielen MMJ, van Schaardenburg D, Reesink HW, et al. Specific autoantibodies precede the symptoms of rheumatoid arthritis: A study of serial measurements in blood donors. Arthritis Rheum. 2004; 50:380-6. DOI: 10.1002/art.20018 [PubMed: 14872479]

8. van der Woude D, Rantapää-Dahlqvist S, Ioan-Facsinay A, et al. Epitope spreading of the anticitrullinated protein antibody response occurs before disease onset and is associated with the disease course of early arthritis. Ann Rheum Dis. 2010; 69:1554-61. DOI: 10.1136/ard.2009.124537 [PubMed: 20448290]

9. van de Stadt LA, de Koning MHMT, van de Stadt RJ, et al. Development of the anti-citrullinated protein antibody repertoire prior to the onset of rheumatoid arthritis. Arthritis Rheum. 2011; 63:3226-33. DOI: 10.1002/art.30537 [PubMed: 21792832]

10. Sokolove J, Bromberg R, Deane KD, et al. Autoantibody Epitope Spreading in the Pre-Clinical Phase Predicts Progression to Rheumatoid Arthritis. PLoS ONE. 2012; 7doi: 10.1371/ journal.pone.0035296

11. Suwannalai P, van de Stadt LA, Radner H, et al. Avidity maturation of anti-citrullinated protein antibodies in rheumatoid arthritis. Arthritis Rheum. 2012; 64:1323-8. DOI: 10.1002/art.33489 [PubMed: 22130974]

12. Rombouts Y, Ewing E, van de Stadt LA, et al. Anti-citrullinated protein antibodies acquire a proinflammatory Fc glycosylation phenotype prior to the onset of rheumatoid arthritis. Ann Rheum Dis. 2015; 74:234-41. DOI: 10.1136/annrheumdis-2013-203565 [PubMed: 24106048]

13. Willemze A, Trouw LA, Toes REM, et al. The influence of ACPA status and characteristics on the course of RA. Nat Rev Rheumatol. 2012; 8:144-52. DOI: 10.1038/nrrheum.2011.204 [PubMed: 22293763]

14. Schett G, Emery P, Tanaka Y, et al. Tapering biologic and conventional DMARD therapy in rheumatoid arthritis: current evidence and future directions. Ann Rheum Dis. 2016; 75:1428-37. DOI: 10.1136/annrheumdis-2016-209201 [PubMed: 27261493]

15. Ursum J, Bos WH, van Dillen N, et al. Levels of anti-citrullinated protein antibodies and IgM rheumatoid factor are not associated with outcome in early arthritis patients: a cohort study. Arthritis Res Ther. 2010; 12:R8.doi: 10.1186/ar2907 [PubMed: 20064278]

16. Burr ML, Viatte S, Bukhari M, et al. Long-term stability of anti-cyclic citrullinated peptide antibody status in patients with early inflammatory polyarthritis. Arthritis Res Ther. 2012; 14:R109.doi: 10.1186/ar3834 [PubMed: 22571727]

17. Barra L, Bykerk V, Pope JE, et al. Anticitrullinated protein antibodies and rheumatoid factor fluctuate in early inflammatory arthritis and do not predict clinical outcomes. J Rheumatol. 2013; 40:1259-67. DOI: 10.3899/jrheum.120736 [PubMed: 23378461]

18. Rönnelid J, Wick MC, Lampa J, et al. Longitudinal analysis of citrullinated protein/peptide antibodies (anti-CP) during 5 year follow up in early rheumatoid arthritis: anti-CP status predicts worse disease activity and greater radiological progression. Ann Rheum Dis. 2005; 64:1744-9. DOI: 10.1136/ard.2004.033571 [PubMed: 15843452] 
19. de Moel EC, Derksen VFAM, Trouw LA, et al. In RA, becoming seronegative over the first year of treatment does not translate to better chances of drug-free remission. Ann Rheum Dis. Published Online First: 25 July 2018

20. Arnett FC, Edworthy SM, Bloch DA, et al. The american rheumatism association 1987 revised criteria for the classification of rheumatoid arthritis. Arthritis Rheum. 1988; 31:315-24. DOI: 10.1002/art.1780310302 [PubMed: 3358796]

21. Aletaha D, Neogi T, Silman AJ, et al. 2010 rheumatoid arthritis classification criteria: an American College of Rheumatology/European League Against Rheumatism collaborative initiative. Ann Rheum Dis. 2010; 69:1580-8. DOI: 10.1136/ard.2010.138461 [PubMed: 20699241]

22. Verpoort KN, Cheung K, Ioan-Facsinay A, et al. Fine specificity of the anti-citrullinated protein antibody response is influenced by the shared epitope alleles. Arthritis Rheum. 2007; 56:3949-52. DOI: 10.1002/art.23127 [PubMed: 18050209]

23. Ioan-Facsinay A, Willemze A, Robinson DB, et al. Marked differences in fine specificity and isotype usage of the anti-citrullinated protein antibody in health and disease. Arthritis Rheum. 2008; 58:3000-8. DOI: 10.1002/art.23763 [PubMed: 18821680]

24. Ursum J, Bos WH, van de Stadt RJ, et al. Different properties of ACPA and IgM-RF derived from a large dataset: further evidence of two distinct autoantibody systems. Arthritis Res Ther. 2009; 11:R75.doi: 10.1186/ar2704 [PubMed: 19460147]

25. Kastbom A, Strandberg G, Lindroos A, et al. Anti-CCP antibody test predicts the disease course during 3 years in early rheumatoid arthritis (the Swedish TIRA project). Ann Rheum Dis. 2004; 63:1085-9. DOI: 10.1136/ard.2003.016808 [PubMed: 15308517]

26. Bos WH, Bartelds GM, Wolbink GJ, et al. Differential response of the rheumatoid factor and anticitrullinated protein antibodies during adalimumab treatment in patients with rheumatoid arthritis. J Rheumatol. 2008; 35:1972-7. [PubMed: 18785316]

27. Bobbio-Pallavicini F, Alpini C, Caporali R, et al. Autoantibody profile in rheumatoid arthritis during long-term infliximab treatment. Arthritis Res Ther. 2004; 6:R264-272. DOI: 10.1186/ ar1173 [PubMed: 15142273]

28. Alessandri C, Bombardieri M, Papa N, et al. Decrease of anti-cyclic citrullinated peptide antibodies and rheumatoid factor following anti-TNFalpha therapy (infliximab) in rheumatoid arthritis is associated with clinical improvement. Ann Rheum Dis. 2004; 63:1218-21. DOI: 10.1136/ ard.2003.014647 [PubMed: 15361374]

29. Bobbio-Pallavicini F, Caporali R, Alpini C, et al. High IgA rheumatoid factor levels are associated with poor clinical response to tumour necrosis factor alpha inhibitors in rheumatoid arthritis. Ann Rheum Dis. 2007; 66:302-7. DOI: 10.1136/ard.2006.060608 [PubMed: 17079248]

30. Böhler C, Radner H, Smolen JS, et al. Serological changes in the course of traditional and biological disease modifying therapy of rheumatoid arthritis. Ann Rheum Dis. 2013; 72:241-4. DOI: 10.1136/annrheumdis-2012-202297 [PubMed: 23087181]

31. Vis M, Bos WH, Wolbink G, et al. IgM-rheumatoid factor, anti-cyclic citrullinated peptide, and anti-citrullinated human fibrinogen antibodies decrease during treatment with the tumor necrosis factor blocker infliximab in patients with rheumatoid arthritis. J Rheumatol. 2008; 35:425-8. [PubMed: 18322974]

32. Verpoort KN, Jol-van der Zijde CM, Papendrecht-van der Voort EaM, et al. Isotype distribution of Anti-Cyclic citrullinated peptide antibodies in undifferentiated arthritis and rheumatoid arthritis reflects an ongoing immune response. Arthritis Rheum. 2006; 54:3799-808. DOI: 10.1002/ art.22279 [PubMed: 17133560]

33. Toes REM, Huizinga TJW. Update on autoantibodies to modified proteins. Curr Opin Rheumatol. 2015; 27:262-7. DOI: 10.1097/BOR.0000000000000166 [PubMed: 25760280]

34. van Nies JAB, Brouwer E, van Gaalen FA, et al. Improved early identification of arthritis: evaluating the efficacy of Early Arthritis Recognition Clinics. Ann Rheum Dis. 2013; 72:1295301. DOI: 10.1136/annrheumdis-2012-202289 [PubMed: 22952388] 


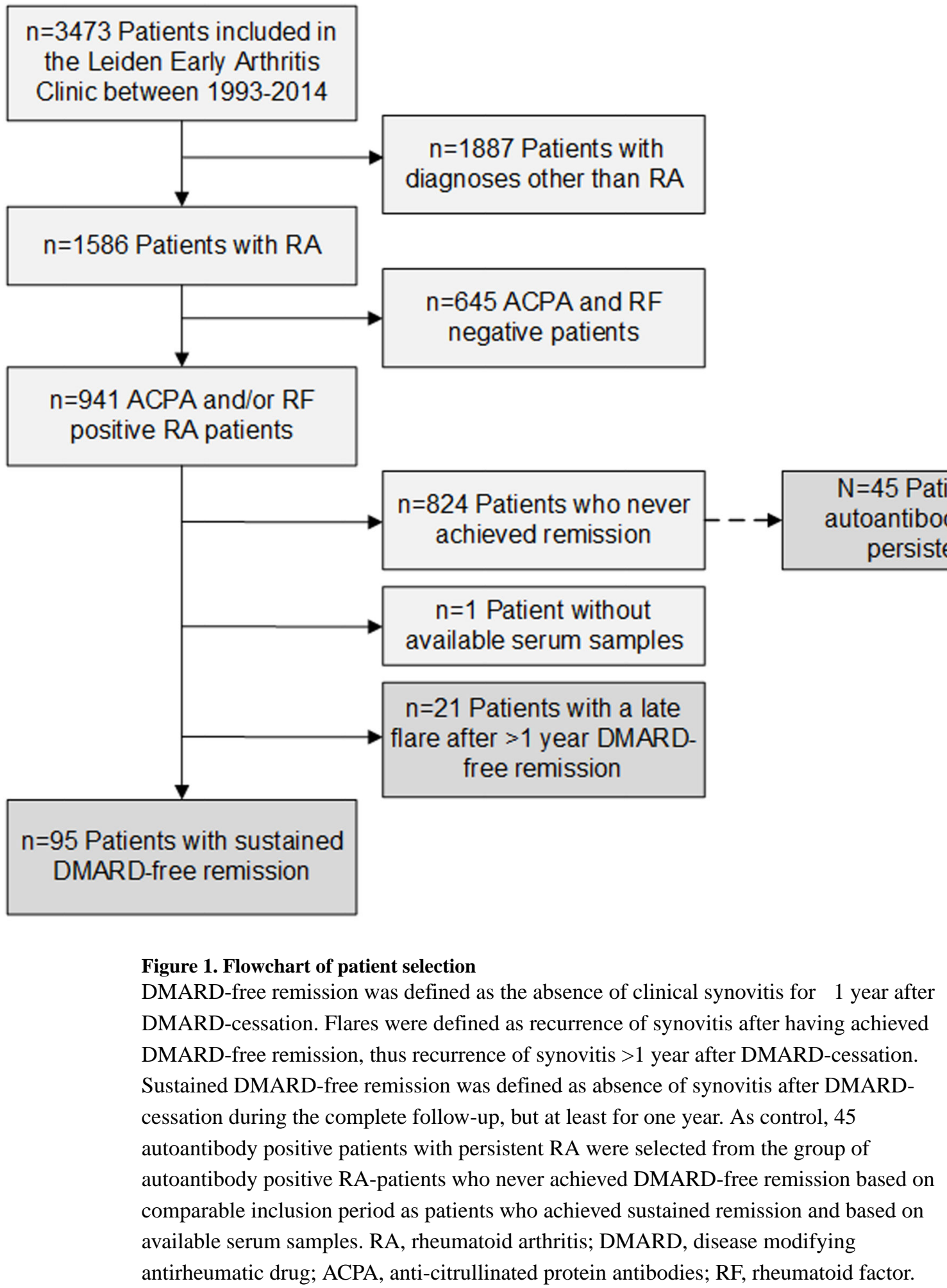


A

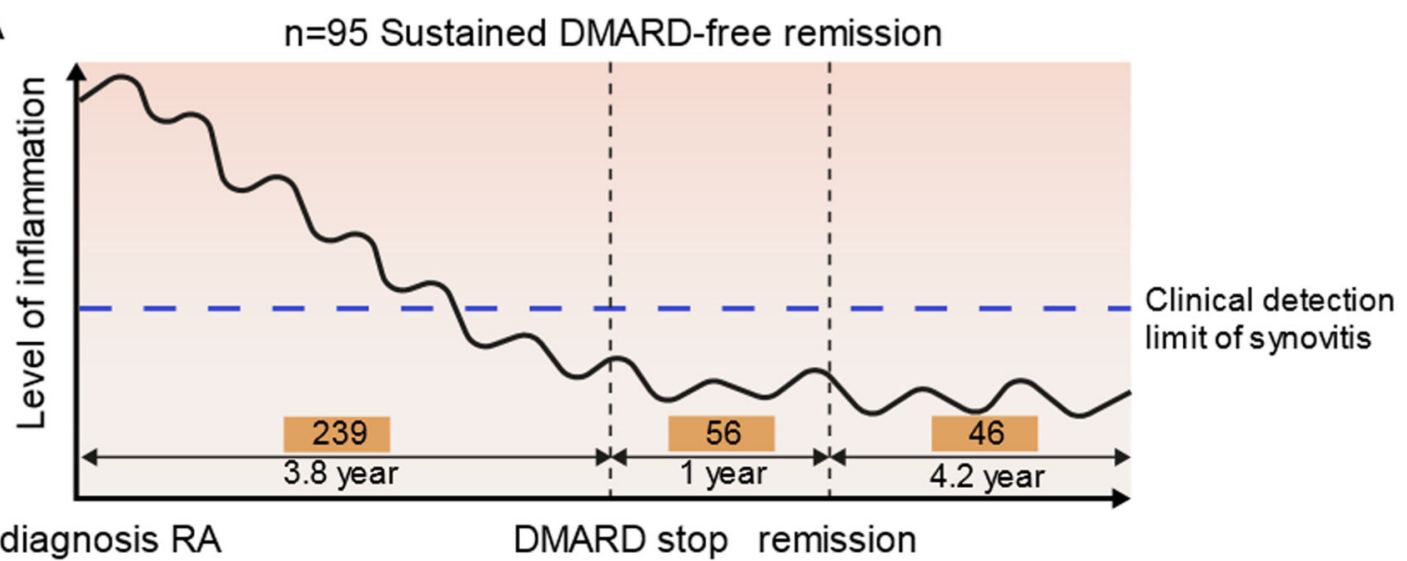

B

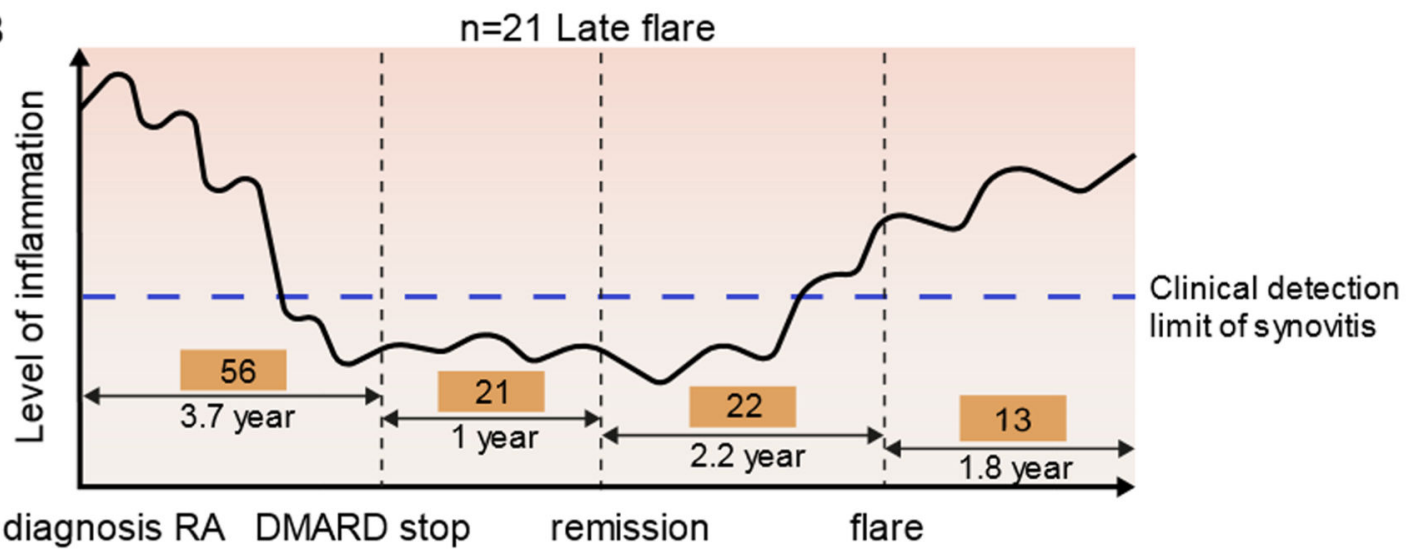

C

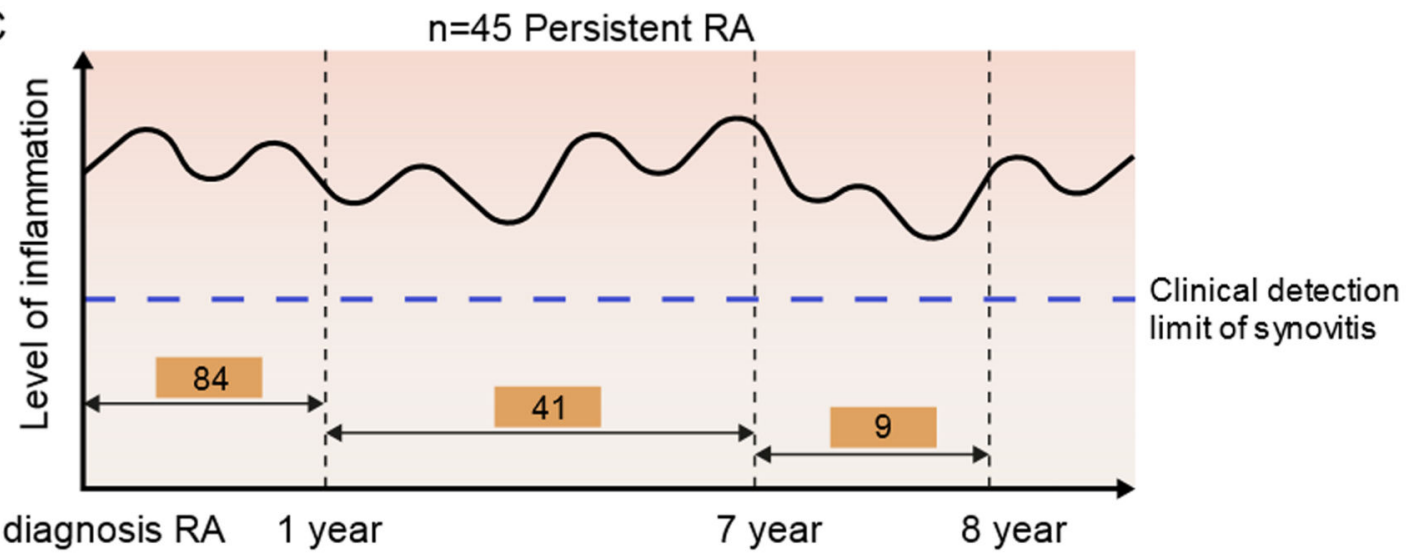

Figure 2. Overview of samples measured during follow-up of patients who achieved sustained DMARD-free remission (A), patients with a late flare (B) and patients with persistent RA (C) Numbers indicate the number of samples measured within the indicated time periods. In total, 587 samples were measured. Of patients who achieved sustained DMARD-free remission, samples were obtained at diagnosis, before and at or after achieving remission. 
A

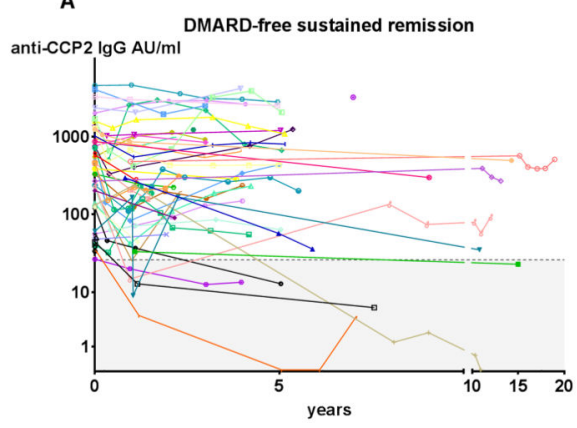

B

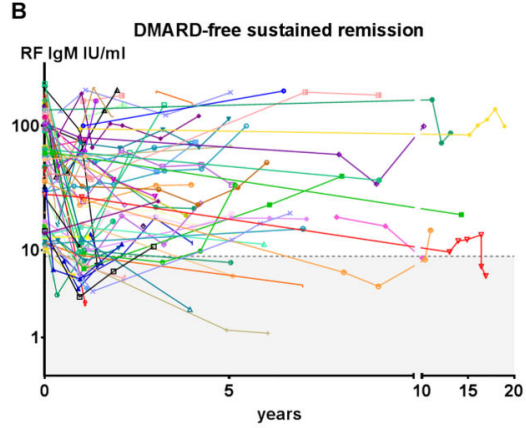

Flare
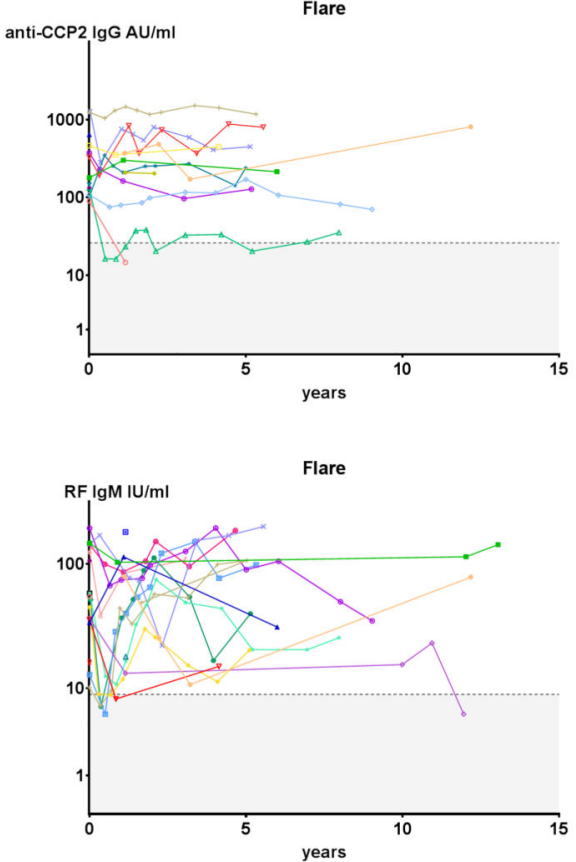

Persistent RA

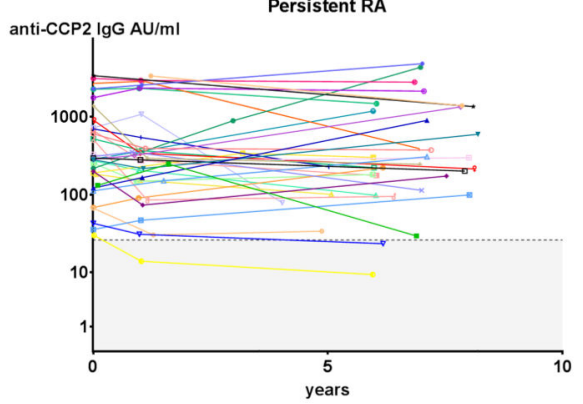

Persistent RA

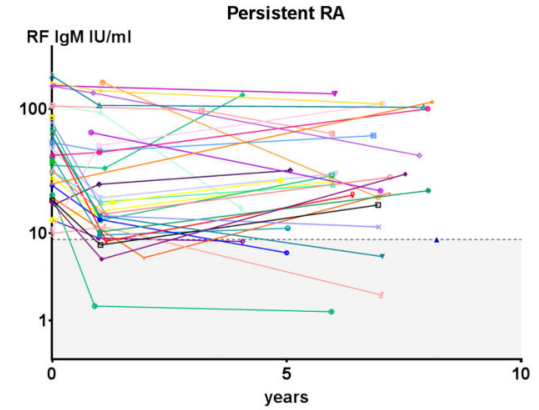

Figure 3. Anti-CCP2 IgG levels in ACPA-positive RA-patients (A) and RF IgM levels in RFpositive patients (B) during follow-up, stratified for clinical outcome Dotted lines indicate the cut-off values (25 AU/ml for anti-CCP2 IgG and $8 \mathrm{IU} / \mathrm{ml}$ for RF IgM). Values below the detection limit were imputed with the value of zero. Number of ACPA and RF positive patients in each group: DMARD-free sustained remission: ACPA+ $n=54, R F+n=86$, flare: $A C P A+n=15, R F+n=21$, persistent $R A: A C P A+n=35, R F+n=41$. ACPA, anti-citrullinated protein antibodies; RA, rheumatoid arthritis; RF, rheumatoid factor; DMARD, disease modifying antirheumatic drug. 

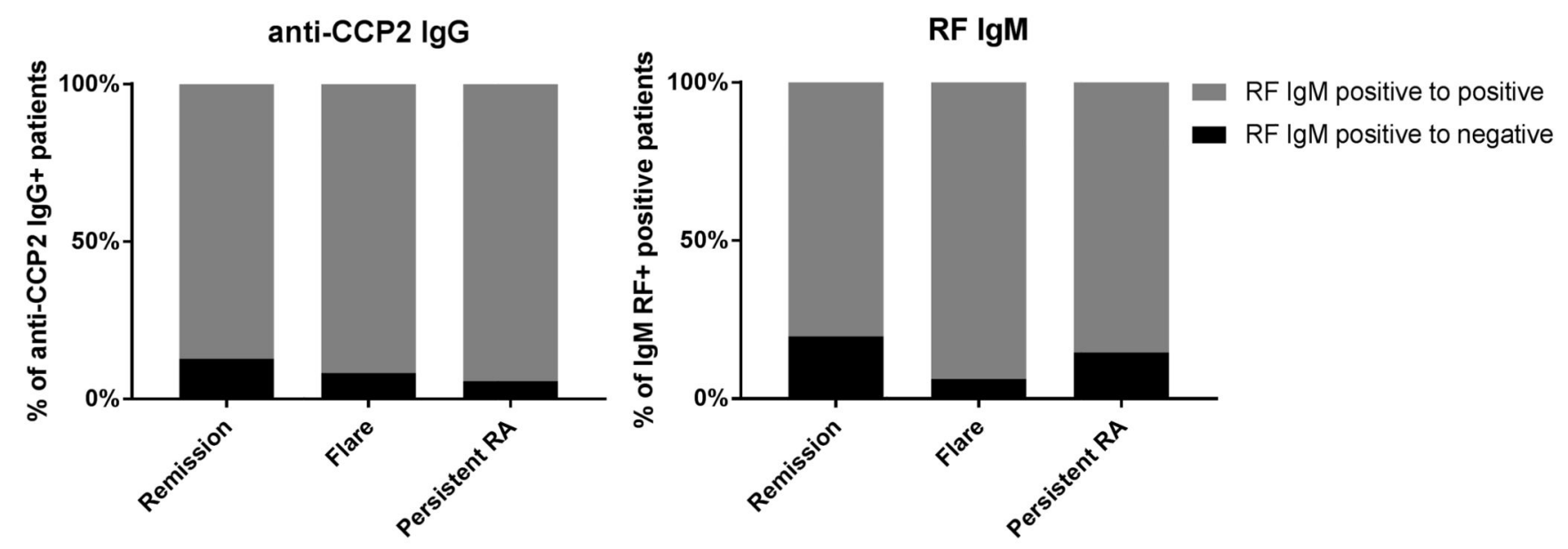

Figure 4. Reversion to anti-CCP2 IgG (A) and RF IgM (B) seronegativity in autoantibody positive RA-patients who achieved sustained DMARD-free remission, who had a late flare and in patients with persistent $R A$

Analyses were performed in patients positive for anti-CCP2 IgG (A) or positive for RF IgM. Seroreversion was defined as shifting from seropositive at baseline to seronegative in the last available serum sample; for patients who achieved sustained DMARD-free remission the last sample was measured at the time of remission. Number of patients in each group: DMARD-free sustained remission: $A C P A+n=47, R F+n=71$, late flare: $A C P A+n=12, R F+$ $n=16$, persistent RA: ACPA $+n=35, R F+n=41$. Anti-CCP2, anti-cyclic citrullinated peptide 2; RF, rheumatoid factor; DMARD, disease modifying antirheumatic drug; RA, rheumatoid arthritis. 


\section{anti-CCP2 IgM}

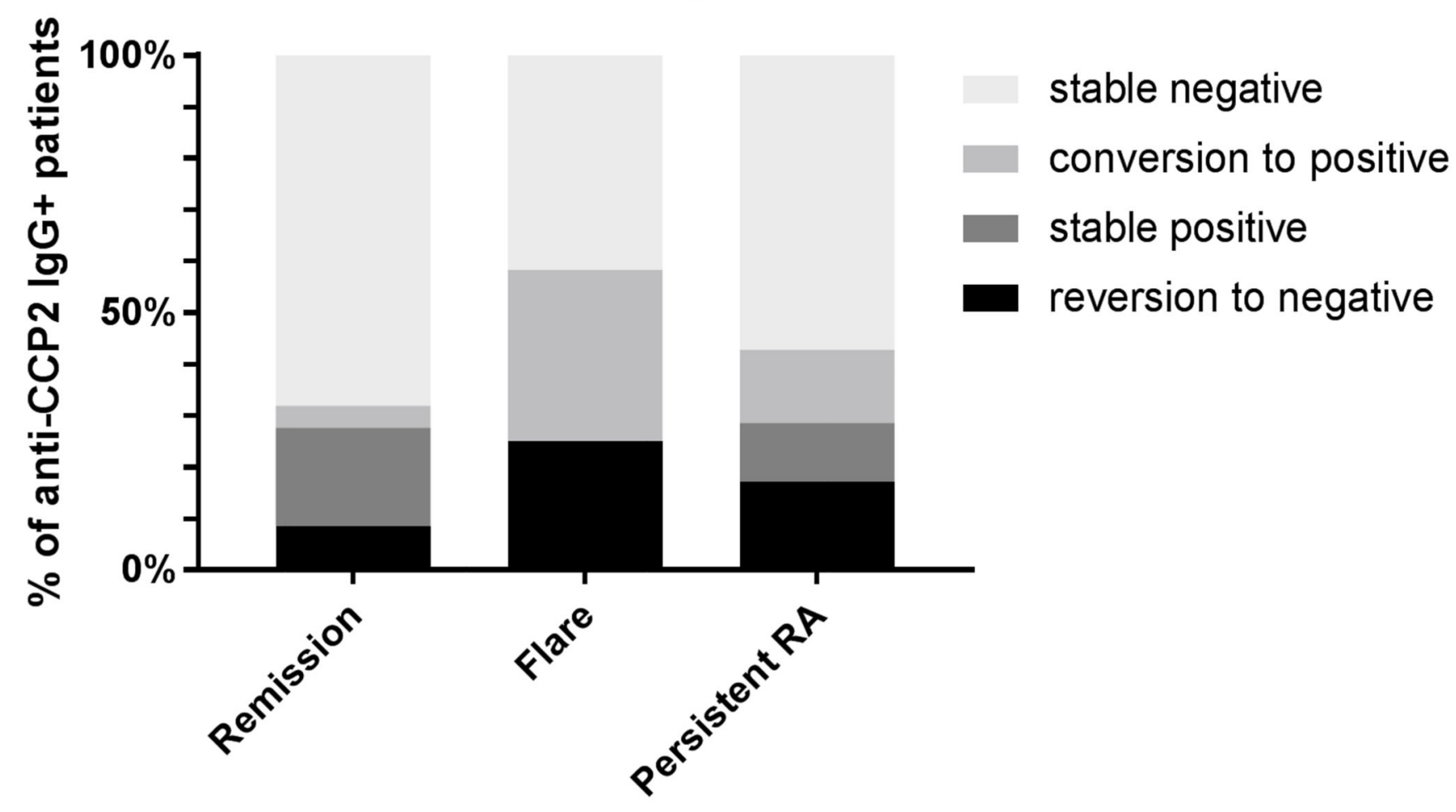

Figure 5. Change in anti-CCP2 IgM status during follow-up in patients who achieved DMARDfree sustained remission, who had a flare and in patients with persistent $R A$

Data are shown for the subgroup of anti-CCP2 IgG+ patients at baseline. Number of patients in each group: DMARD-free sustained remission: $n=47$, flare: $n=12$, persistent RA: $n=35$. Anti-CCP2, anti-cyclic citrullinated peptide 2; DMARD, disease modifying antirheumatic drug; RA, rheumatoid arthritis. 
Table 1

Baseline characteristics of RA-patients who achieved sustained DMARD-free remission, who flared after being in DMARD-free remission and of patients with persistent RA

\begin{tabular}{|c|c|c|c|c|}
\hline & $\begin{array}{l}\text { Sustained DMARD-free } \\
\text { remission }(n=95)\end{array}$ & $\begin{array}{c}\text { Late Flare after } \geq 1 \text { year of } \\
\text { DMARD-free remission } \\
\qquad(n=21)\end{array}$ & Persistent RA (n=45) & p-value \\
\hline Age in years, mean (SD) & $54(17)$ & $52(13)$ & $55(12)$ & 0.63 \\
\hline Female, n (\%) & $65(68)$ & $13(62)$ & $30(67)$ & 0.85 \\
\hline Symptom duration in weeks, median (IQR) & $17(10-35)$ & $20(8-37)$ & $20(13-38)$ & 0.56 \\
\hline 66-SJC, median (IQR) & $5(3-9)$ & $5(2-13)$ & $5(3-8)$ & 0.81 \\
\hline 68-TJC, median (IQR) & $8(3-13)$ & $12(4-15)$ & $5(4-11)$ & 0.32 \\
\hline Autoantibody status & & & & 0.047 \\
\hline $\mathrm{ACPA}+\mathrm{RF}-, \mathrm{n}(\%)$ & $9(9)$ & $0(0)$ & $4(9)$ & \\
\hline ACPA- RF+, n(\%) & $41(43)$ & $6(29)$ & $10(22)$ & \\
\hline $\mathrm{ACPA}+\mathrm{RF}+, \mathrm{n}(\%)$ & $45(47)$ & $15(71)$ & $31(69)$ & \\
\hline CRP (mg/L), median (IQR) & $11(3-28)$ & $11(4-23)$ & $14(5-40)$ & 0.39 \\
\hline $\operatorname{ESR}(\mathrm{mm} / \mathrm{h})$, median $(\mathrm{IQR})$ & $26(14-49)$ & $29(13-44)$ & $29(20-41)$ & 0.75 \\
\hline
\end{tabular}

Patients with persistent RA were selected from the group of autoantibody RA-patients who never achieved DMARD-free remission based on comparable inclusion period as patients who achieved sustained remission and based on available serum samples. DMARD, disease modifying antirheumatic drug; SD, standard deviation; IQR, interquartile range; SJC, 66-swollen joint count; TJC, 68-tender joint count; CRP, C-reactive protein; RF, rheumatoid factor; ACPA, anti-citrullinated protein antibodies; RA, rheumatoid arthritis; symptom duration, time between symptom onset and inclusion in cohort 